\title{
ERCP with a cap-assisted gastroscope for an intradiverticular ampulla
}

An 84-year-old woman with a history of Alzheimer's dementia, hypothyroidism, and cholecystectomy presented to the emergency room with ascending cholangitis. She had undergone a percutaneous biopsy of a "liver cyst" 2 days earlier at an outside facility. Magnetic resonance imaging at our hospital showed a lobulated 6 -cm cyst in segment 6/7 ( $\triangleright$ Fig. 1 a). Other findings included a dilated common bile duct $(12 \mathrm{~mm}$ ) with choledocholithiasis and a $5-\mathrm{cm}$ diverticulum in the second portion of the duodenum ( $\triangleright$ Fig. $1 \mathrm{~b})$.

During endoscopic retrograde cholangiopancreatography (ERCP), evaluation of the ampulla with a side-viewing duodenoscope revealed the large diverticulum with the major ampulla located in its rim. The opening of the ampulla pointed in an acute angle toward the diverticular lumen (> Fig.2), thus making cannulation with the duodenoscope extremely difficult. Therefore, the decision was made to perform the procedure using a cap-fitted gastroscope ( $\vee$ Video 1 ).

The patient did not have any complications after the ERCP and was discharged 2 days later. As per the wishes of the pa- tient's family, no further interventions were performed to establish the histology of the hepatic lesion.

The prevalence of periampullary diverticulum (PAD) has been estimated to be around $65 \%$ among elderly patients [1]. They are usually asymptomatic, but can rarely cause biliary obstruction, pancreatitis or perforation. A PAD makes cannu- lation during ERCP challenging due to unusual angulation of the ampulla or inability by the endoscopist to locate it. Cannulation techniques described to approach a PADinclude: percutaneous and endoscopic ultrasound-guided rendezvous, reversed guidewire, two-devices in one-channel, endoclip-assisted, double endoscope, and cap-assisted cannula-

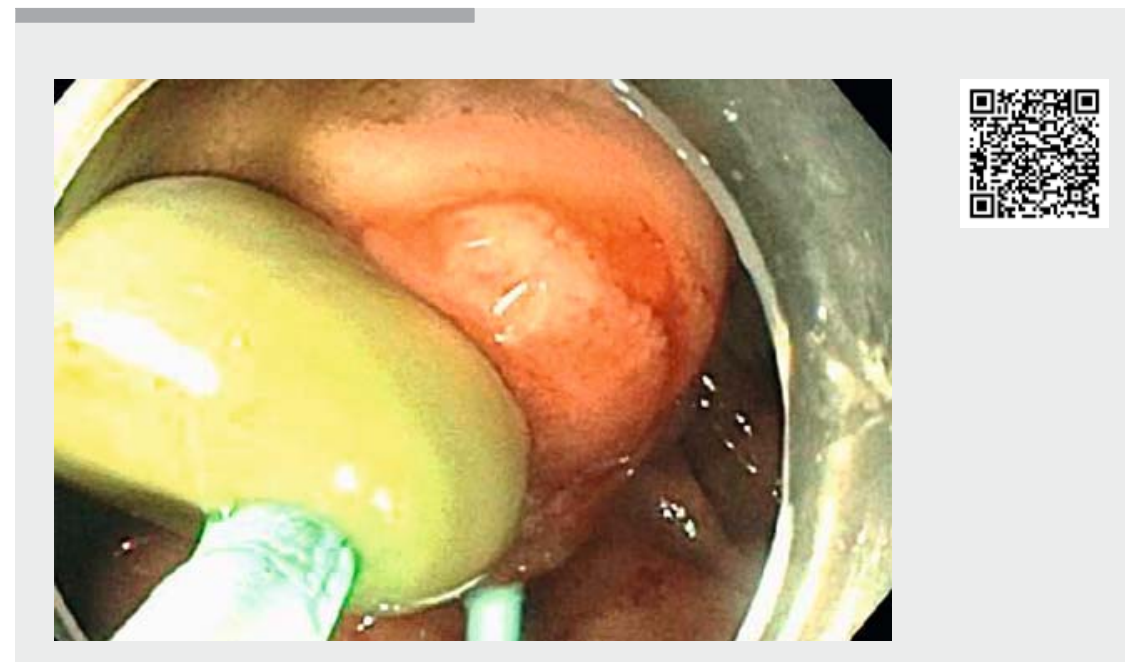

Video 1 Endoscopic retrograde cholangiopancreatography with a cap-fitted gastroscope.
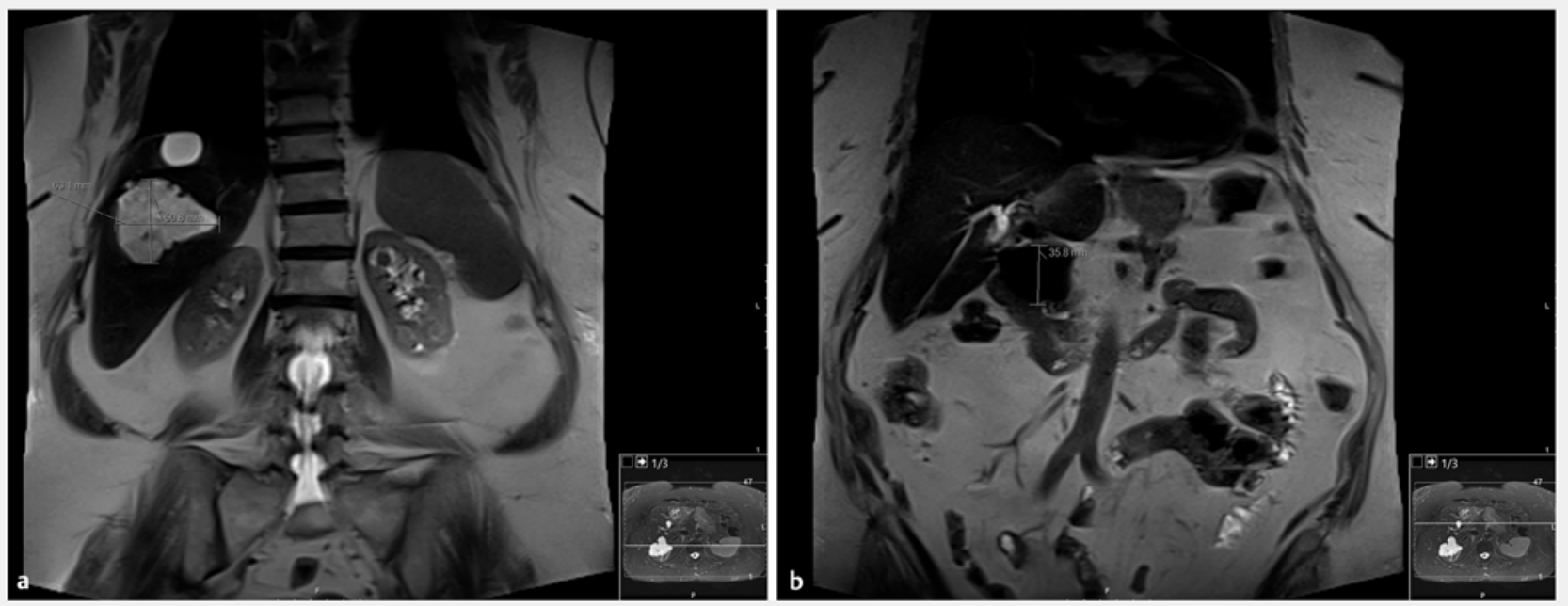

- Fig. 1 Magnetic resonance imaging. a Hepatic cyst. b Duodenal diverticulum. 


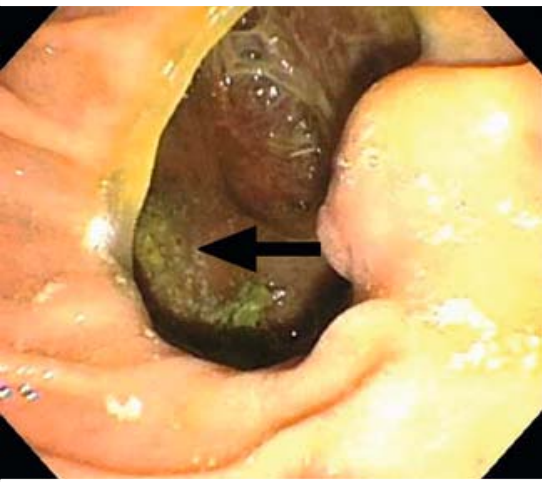

- Fig.2 Ampulla pointing (arrow) toward the diverticular lumen. Duodenoscope view.

tion [2]. We prefer the cap-assisted technique because of its relative simplicity. Successful cannulation of the bile duct was achieved in $100 \%$ of cases in two recent case series, although in one of them only $50 \%$ of the ERCPs were performed entirely through the gastroscope $[3,4]$.

Endoscopy_UCTN_Code_TTT_1AR_2AC
Competing interests

\section{None}

The author

\section{Antonio Mendoza Ladd}

Gastroenterology, Texas Tech University Health Sciences Center, El Paso, Texas, United States

\section{Corresponding author}

\section{Antonio Mendoza Ladd, MD}

Gastroenterology, Texas Tech University Health Sciences Center, El Paso, 4800 Alberta Avenue, El Paso, TX 79905, United States

Fax: +1-915-2155289

dr_ladd25@yahoo.com

\section{References}

[1] Shemesh E, Klein E, Czerniak A et al. Endoscopic sphincterotomy in patients with gallbladder in situ: the influence of periampullary duodenal diverticula. Surgery 1990; 107: $163-166$

[2] Altonbary AY, Bahgat MH. Endoscopic retrograde cholangiopancreatography in periampullary diverticulum: the challenge of cannulation. World J Gastrointest Endosc 2016; 8: 282-287
[3] Park CH, Lee WS, Joo YE et al. Cap-assisted ERCP in patients with a Billroth II gastrectomy. Gastrointest Endosc 2007; 66: 612 615

[4] Myung DS, Park CH, Koh HR et al. Capassisted ERCP in patients with difficult cannulation due to periampullary diverticulum. Endoscopy 2014; 46: 352 - 355

\section{Bibliography}

DOI https://doi.org/10.1055/a-0999-5063

Published online: 17.9.2018

Endoscopy 2020; 52: E61-E62

(c) Georg Thieme Verlag KG

Stuttgart · New York

ISSN 0013-726X

\section{ENDOSCOPY E-VIDEOS}

https://eref.thieme.de/e-videos

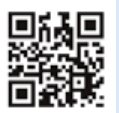

Endoscopy E-Videos is a free access online section, reporting on interesting cases and new techniques in gastroenterological endoscopy. All papers include a high quality video and all contributions are freely accessible online.

This section has its own submission website at

https://mc.manuscriptcentral.com/e-videos 